\title{
North American Women's Marital Surname Change: Practices, Law, and Patrilineal Descent Reckoning
}

\author{
Melanie MacEacheron ${ }^{1}$ (D) \\ Published online: 15 March 2016 \\ (C) Springer International Publishing 2016
}

1985 (MacClintock 2010, and see Snyder 2009)? Further, why does the custom persist even though the decision to change surname at marriage is fraught or difficult for many women, for example, because of perceived loss of identity (see, e.g., Boxer and Gritsenko 2005; Robnett and Leaper 2013), and may carry negative economic consequences in the workplace (see generally Goldin and Shim 2004)? This review will attempt to shed light on these questions, via discussion of the history of the custom, its practice, and attitudes toward it in these two countries, in which it is best studied.

Specifically, this article reviews and contextualizes brides' marital surname retention/change within these countries, relating it to a greater assurance of the receipt of a maternal and/ or paternal surname by the children of the marriage. To accomplish this, it reviews and contextualizes each primary, quantitative finding from all peer-reviewed articles published found via my search method, concerning North American women's marital surname change. My ultimate intention is to explain why the practice of women's marital surname change exists, in terms of what evolutionary advantage it confers. The circumstances of its origin, as well as the circumstances under which the practice tends to be retained/not retained, are included in order to bolster this explanation.

My thesis is that the practice exists because it allows brides to signal to grooms an assurance of continuing the practice of tracing descent of the children of the marriage via (predominantly) the male line (patrilineal descent reckoning: Murdock 1949). It thereby enhances recruitment by these wives of husbands' and in-laws' investment to the children of their marriages. Patrilineal descent reckoning, in this case, will be argued to function as such an in-law recruitment enhancer, due to differential grandparental solicitude: the greater investment in grandchildren by grandparents with greater assurance of genetic relatedness (Smith 1988b).

Secondarily, I will advocate for research concerning different rates of women's marital surname change between similar (sub)jurisdictions. In this paper, the utility of this approach is

\footnotetext{
Psychology Department, University of Western Ontario, London, ON N6A 5C2, Canada
}

Melanie MacEacheron
mmaceacheron@gmail.com 
explored by comparing the U.S.A. and Canada, and particularly the states and provinces of these, in such rates. These jurisdictions were chosen for coverage due to their great cultural (historical, legal, and linguistic) similarities and geographical proximity, yet differing women's marital surname change rates (e.g., MacEacheron 2011). (Mexico and Central America are not included, due to their distinctiveness from the U.S.A. and Canada in these regards, and distinct surnaming practice: see, e.g., Fuster 1986.) Where jurisdictions share much in common, if they differ in a custom (such as women's marital surname change) then correlates of the custom as measured at jurisdictional level may shed light on its causes.

\section{Organization of Contents}

The first portion of the paper consists of a primer concerning the ultimate origins of the custom in the U.S.A. and Canada, and potential, broader relevance of the practice. A review of origins is included in part to provide evidence the custom's genesis is better explained by its greater ability, compared with previous surnaming practice, to help women advertise they will surname children of their marriages after their husbands, than by a current explanation posited in the legal literature. Following this, is discussion of current differences in law concerning women's marital surname change and surnaming of children, between North American (sub)jurisdictions. This section is included for background, as well as to show the administrative cost entailed for women undergoing marital surname change. Third, the posited decrease in patrilineal descent reckoning in response to greater equalization of the sexes' reproductive success variances (Ellison 1994; Jackson 2014) and decreased hypergamy (the marrying of women to better-resourced men: Jackson 2014) will be described. Fourth, grandparental discriminative solicitude, or the greater solicitousness of classes of grandparents with greater assurance of relatedness to the grandchild (Smith 1988b), will be described in relationship to women's marital surname retention/ change practice. This will be done, in order to elucidate these factors as potential reasons for recent decreases in patrilineal descent reckoning in North America, as evidenced by greater women's marital surname retention (and hyphenation). Fifth, the primary, quantitative result of each social scientific study deemed to chiefly concern North American attitudes concerning or practice of women's marital surname change (located by my search $\operatorname{method}^{1}$ ) will be reviewed, and contextualized as

\footnotetext{
${ }^{1}$ All peer-reviewed, social scientific articles found within broad searches of 16 social science search engines, plus an updating search on Google Scholar, which facially could have primarily concerned attitudes to women's marital surname change or its practice in North America were reviewed. Other articles referenced therein, including legal articles, which based on their references could have concerned women's marital surname change in North America were also reviewed. Other (e.g., qualitative) findings were also included where they were deemed relevant to the discussion. Full details of all search parameters are available from the author.
}

appropriate within the framework of wives' enhancement of their resource recruitment for the children of their marriages, from husbands and in-laws.

Women's and not men's marital surname change will be reviewed, owing partially to the fact that U.S. men almost never engage in it (Snyder 2009). The other reason for this limiting of the review, is that only women's marital surname change is a persistent tradition. As such, it would seem more likely than one that may pass swiftly to shed light on evolved psychology. Finally, in the Discussion, specific, further research examining patrilineal descent reckoning and recruitment of investment by wives in the children of their marriages from husbands and in-laws will be recommended.

\section{Background}

\section{Historical Origins and Cross-Cultural Relevance of Women's Marital Surname Change}

Transmission of father's surname to children began in France around the year 1000, and in England at about the time of the Norman conquest of 1066. The practice, however, did not become general in England until the reign of Edward II (13071327). Adoption of their husbands' surnames by English women became widespread in the eleventh and twelfth centuries (Embleton and King 1984). That is, it became widespread at the same time or soon after the custom of transmission of father's surname to children began in that country. Previous to such transmission, patronymy, or the giving of first names to children indicating their father's identity (e.g., by attaching a suffix to the father's first name or preceding it with 'son of' or similar) had been the common practice in England (Camden and Philipot 1637). On its face, patronymy is a manifestation of patrilineal descent reckoning, though via it only one member of the patriline - the father-is identifiable.

In most states and provinces of the U.S.A. and Canada, under the legal doctrine of coverture inherited from English common law, a wife's legal identity was subsumed under that of her husband. The surnaming of wives after their husbands has been regarded by previous legal scholars as a natural outcome of such doctrine (e.g., MacClintock 2010). Coverture may have been modeled to a degree on more ancient law (Roman law: e.g., Zaher 2002) which could, at least theoretically, also have given rise to the French tradition of surnaming children for their fathers. Still, given that the custom of surnaming children for their fathers (in France) would appear to predate all English common law (van Caenegem 1988), any doctrine of the latter is suspect as a cause of the former. Although widespread taking of husbands' surnames at marriage by women seems to have predated the establishment of the custom of transmission of fathers' surnames to children in England, that the former facilitated the latter appears to be a better explanation of the practice than coverture. 
Although surname transmission from father to child is not universal, a sampling of type of descent reckoning, world-over, has shown more than twice as many patrilineal $(42 \%)$ as matrilineal $(20 \%)$ societies, with the remainder practicing some form of bilateral (from both the mother's and father's sides of the family: $36 \%$ ) or bilineal (using only matriline and patriline) descent reckoning (Murdock 1949). In patrilineal societies, women are transferred, in some sense, from their natal families to those of their new husbands (Murdock 1949). These practices have characterized a majority of human societies, and an even larger majority of human individuals, as large nation states and colonial powers are patrilineal, whereas matrilineal societies are small. In patrilineal societies, children and wives are often labeled in ways that indicate the patrilineage into which they were born or married, respectively. Contemporary marital surnaming would appear to have arisen from such practices. Surname transmission down the male line would seem to be but one means of asserting and/or tracing patrilineality: practices that must exist in all patrilineal societies. As such, the study of surname transmission, as discussed in this paper, has relevance to all patrilineal societies, and not just to those in which it is practiced.

\section{Recent and Current U.S. and Canadian ${ }^{2}$ Legal History: The Relative Ease of Marital Surname Retention}

Only between the mid-1970s and mid-1980s did it become legal for a married woman to retain her natal surname for all purposes, in all U.S. states. Canada has generally been more permissive than the U.S.A. in allowing choice for women between marital surname retention and change (MacClintock 2010). As a close neighbor, however, Canada's customs surrounding surname change have no doubt been greatly affected by the U.S. legal situation.

In Canada, all territories and provinces other than Quebec explicitly note that a woman need not change her surname upon marriage, and that she may assume/adopt that of her husband without having to undergo a legal name change (e.g., Government of Alberta n.d.; Government of British Columbia n.d.; Government of Manitoba n.d.; Government of Ontario n.d.a; Karen Kieley, Research and Statistical

\footnotetext{
${ }^{2}$ No Canadian, peer-reviewed legal article primarily concerning the condition of that country's or its provinces'/territories' laws on women's marital surname change was found. As such, a province-by-province/ territory-by-territory search of government websites was conducted, to find official policy and, in some cases, published statistics on such practice. Where no policy on women's marital surname change was found on provincial/territorial websites, direct inquiries were made to these governments. Legal articles were included as necessary to supplement the literature reviewed.
}

Officer, Vital Statistics, Service Nova Scotia and Municipal Relations, personal communication, November 19, 2007). Under Quebec civil law as of 1980 marriage is not enumerated as a ground for legal name change, though a wife may use her husband's name socially (Civil Code of Québec, C.c.Q., 1991, c. 64, a. 58: Céline Therrien and Lise Leblanc, Centre de communications avec la clientele, Ministère de la Justice du Québec, personal communications, November 20, 2007 and January 11, 2008, respectively).

Name changes in the U.S.A. are under state jurisdiction, resulting in variation between states in women's marital surname change law and practice (MacClintock 2010). The state of Louisiana, though legally similar to Quebec in stance on this issue, in practice does not impede a woman's use of a surname changed to that of a spouse more than any other state (MacClintock 2010). In both countries, one legally entitled to assume/adopt a marital surname, in order to do so, must usually send proof of marriage plus a name change request to all parties with which he or she deals under his or her name and under which he or she has identifying documents (e.g., Government of Ontario n.d.a.; Goldin and Shim 2004; see also MacClintock 2010). Those legally changing surname, in addition to taking these actions, must first pass a court hurdle. Canadians (outside Quebec) must make a successful court application for name change (e.g., Government of Ontario n.d.b.). In the U.S.A., legal name change can generally be effected via petition to the state court which is approved by a judge (MacClintock 2010). Birth surname retention, on the other hand, is automatic and effortless.

\section{Decreases in Each of Inter-Sexual Difference in Reproductive Success Variance and Hypergamy}

In the U.S.A., patrilineal descent, or passing of resources including eligibility for group membership via the male line (Goody 1961), is limited, at least in very recent times, nearly solely to children taking their (married) father's surname (Stanton 2006). The U.S.A. and other similar, Western nations, presumably including Canada, again in recent times, have been characterized as bilaterally reckoning descent. That is, they are characterized as including all relatives within each individual's lineage (Davenport 1959). According to Schneider and Cottrell (1975), however, despite the fact that U.S. men actually see their mothers' relatives more often than their fathers' (see also Stanton 2006), they are able to name more distant relatives from their father's side of the family than from their mother's. These authors also reported that "... there is a tendency for distant kin to be linked more through father's father than father's mother on the father's side for both male and female informants ..." (at p. 76). This may or may not be due to a shared family name. Either way, however, it constitutes evidence of greater descent reckoning based on paternal than on maternal relatives in North 
America, despite the apparently countering force of increased contact with the latter.

Ellison (1994) and Jackson (2014) both comment relevantly on the potential demise of patrilineal descent reckoning in the modern West. Ellison's analysis is based in part on the advantage, in cultures with relatively high male compared with female reproductive success (usually calculated by tallying one's number of offspring or offspring surviving to adulthood: Brown et al. 2009) variance, of patrilineal over bilateral descent reckoning. Cross-culturally, patrilineal descent reckoning is associated with factors relating to greater male compared with female reproductive success variance (Ellison 1994). Patrilineal descent reckoning is associated, for example, with blood feud, bride price, and rigorous sanctioning of adulterers (Daly and Wilson 1988). Hartung (1976), further, relates the passing of wealth patrilineally as maximizing the number of descendants, where sons might attract multiple wives using this wealth (e.g., in North America, via serial marriage to young women) and thus produce more grandchildren than any daughter could (see also Marlowe 2004; Smith et al. 1987). Hrdy and Judge (1993) cite the patrilineal practice of primogeniture, or bequeathing most or all resources to the eldest son, as best ensuring survival of the (father's and mother's) line in a resource-defense mating system, such as one in which a minimal amount of land is required to support a family and in which land is scarce. Their discussion largely centers on the U.S.A. Sylvester (1998) discusses a similar shift to unigeniture farmland bequests to sons in Canada, albeit with some variation associated with local legal differences (e.g., with husbands leaving relatively more to their widows in order to avoid land partition), under similar circumstances.

Greater male than female reproductive success variance, however, is declining in the modern West with decreased fertility (Ellison 1994), as is the necessity of inheriting property to being able to support a family (see generally Jackson 2014). In Brown et al.'s (2009) cross-cultural review of reproductive success variance between the sexes, the modern U.S. ratio of male to female reproductive success variance is low at 1.27 , ranging up to 4.75 among the Dogon (full range, 0.79-4.75; data regarding Canada, its provinces, and individual U.S. states not available to the author's best knowledge). The genetic advantage attendant on favoring patrilineal inheritance may, thus, be being attenuated in the modern U.S.. If patrilineal descent reckoning stems from patrilineal inheritance, then as the impetus for the latter declines, so should the incidence of the former. Ellison (1994) notes that with the "modern fertility transition" (p. 162) of Western nations to more equal male and female reproductive success variance:

... Bilateral descent becomes the most efficient method of reckoning biological relatedness

... if present trends continue, even the tradition of patronymic identification may seem to us a quaint and ultimately arbitrary cultural artifact rather than an important referent to a dominant kinship structure. (p. 163)

Stanton (2006) and Jackson (2014) also note that less power and fewer resources are directly or indirectly inherited or otherwise bestowed on those of one's lineage under modern conditions. Jackson goes on to relate this to a rise in, among other things, bilateral descent reckoning. Finally, Jackson (2014) notes, patrilineal descent reckoning may be threatened where hypergamy, or the marrying of women to men of greater wealth, education, or status is attenuated, for example, due to women becoming better educated and paid. Under hypergamy, assuming resources are inherited or largely inherited, it behooves children to seek the favor of their wealthier father's family over that of their poorer mother. This may, in turn, lead to or strengthen the importance and salience of patrilineal descent (Jackson 2014).

\section{Differential Grandparental Solicitude}

Notwithstanding the cross-cultural prevalence of patrilineal naming practices and descent reckoning, there is considerable evidence that actual interaction and nurturance exhibit a matrilineal bias when both patrilineal and matrilineal relatives are accessible (e.g., Kahana and Kahana 1970; Robins and Tomanec 1962; Young and Willmott 1957; controlling for proximity, Jackson 1971; Smith 1988a; after divorce, Cherlin and Furstenberg 1986; but see Roberto and Stroes 1992; see also Hill and Hurtado 1996, regarding grandmother presence and grandchild survival). Evolutionists, beginning with Smith (1988b), have interpreted such phenomena as a reflection of adaptive variation in grandparental solicitude. Because paternity is uncertain, maternal grandmothers are the only grandparents with complete certainty of relatedness to the children and should therefore be the most willing to invest. Paternal grandfathers are connected to the children by two uncertain links, and should therefore be least confident of relatedness and least solicitous, while maternal grandfathers and paternal grandmothers are each connected to the children by one certain and one uncertain link, and should therefore be intermediate in solicitude. Several studies have produced data that have been interpreted as supportive of this argument (Smith 1988b; Euler and Weitzel 1996; and see Shackelford et al. 2004; DeKay 1995). In any case, the phenomenon of matrilineal bias in contact, investment and affection is clearly robust in the modern West.

Even in patrilineal societies, matrilateral kin may be more solicitous. Among the hunter-gatherer Hadza of Tanzania, for example, Hawkes et al. (1997) report that the presence of elderly, maternal kin positively affects children's nutrition. Similarly, in a natural-fertility, natural-mortality society in rural Gambia, which was virilocal but in which maternal relatives lived in a relatively easily accessible neighboring village, 
Sear, Mace, and McGregor (2000) report that the only class of relatives other than the mother whose existence had a positive effect on the nutritional status of children was the maternal grandmother (see also Sear et al. 2002). All this begs the question: Even though North Americans have been classed as bilateral descent reckoners, is it possible they tend to include maternal relatives as kin due to solicitude from them, while for their paternal relatives, less or no such solicitude is required? Whether this ought to impact the classification of North Americans' descent reckoning is moot for present purposes. What is being argued here, is that it is a conundrum that North Americans, despite their strong matrilateral ties, still hold as a very strong norm the surnaming of children for the husband of their mother (not the mother herself, instead or additionally), even long after the legal necessity to do so has disappeared (see, e.g., Thornton 1979). This conundrum can be resolved by viewing such surnaming as an attempt at making salient patrilineal descent reckoning, and making maternal relations less salient. But why emphasize the patriline, and would it not risk the maternal relatives' solicitude to do so?

Marriage may be understood as fundamentally a reproductive union (Buckle et al. 1966), inasmuch as it is the context in which children primarily are raised, notwithstanding the tremendous historical and cross-cultural variability in the expectations and practices associated with marriage (Murdock 1949). If, as the evidence reviewed above suggests, contributions from maternal relatives toward a child's well-being are more dependable than contributions from paternal relatives, might patrilineal surnaming be interpreted as a tactic for recruiting patrilineal involvement and investment? Investment by paternal grandparents may increase when grandchildren carry their surname, and this could explain why even the parents of brides are likely to approve of their daughters changing their names at marriage, a fact that might otherwise be deemed puzzling. The importance of such effects is likely to vary in relation to inheritance practices, and to be especially strong where (wealthy) parents leave more resources to sons than to daughters (Smith et al. 1987; see also Chagnon 1979 and Dickemann 1979).

\section{Social Scientific Marital Surname Retention/Change Literature Review}

\section{Inferences Regarding the Psychology of Women Choosing Marital Surname Retention/Change, Men, and the Parents of Each}

Women need not consciously 'know' that they can rely most strongly on their mothers' assistance, less on that of their fathers and mothers-in-law, and least on that of their fathers-inlaw. The proximal reason for women's acting in accordance with such rules may simply be, for example, an evolved tendency for greater closeness between females (and thus between mothers and daughters, but also between mothers-in-law and daughters-in-law) and between people who know each other longer, are related, or both. Based on feelings of closeness alone, a bride may 'know' that the grandparent least willing to help her children will be the paternal grandfather, and that by surnaming these children after their father-in-law, investment prospects will be improved. Married women may seek to improve the quality of their relationships with their in-laws, knowing these could help support these women's children. The quality of the relationship between daughter(-in-law) and parents(in-law), indeed, has been shown to be positively related to the amount and frequency of grandparental involvement with grandchildren (Cherlin and Furstenberg 1986).

Besides possible effects of surnaming on other patrilineal kin, there is evidence that fathers themselves care how their children are named. Besides the enormous prevalence of children actually receiving their fathers' surnames over those of their mothers (Emens 2007; Johnson and Scheuble 2002), Cherlin (1978) found in a non-random survey of American couples who used different surnames and who had a baby or were expecting one, that these couples overwhelmingly gave their child only the father's surname. Cherlin explains the phenomenon as follows: "In most cases, (the mothers) say they didn't care enough to buck their husbands' strong feelings about using their names" (p. 150). In a small study of Canadian unmarried undergraduates, males $(n=31)$ reported caring more than females $(n=32)$ that children receive only their father's surname (Lockwood et al. 2011: see also Robnett and Leaper 2013, in which U.S. undergraduate men more often than women stated they wanted to retain surname at marriage for the reason of "family legacy" or similar). These findings accord with that of Liss and Erchull (2012) that feminist, heterosexual mothers gave their children solely the latter's father's surname at a significantly greater frequency, than otherwise similar women who were not mothers but anticipated having children reported that they would (see also Nugent 2010). That acceding to husbands' preferences in this regard actually influences their commitment and investment is harder to prove, but there is some evidence suggesting that it may. Furstenberg and Talvitie (1980: see also Cherlin and Furstenberg 1986) found that giving the father's first or middle name to the sons of unmarried, young. African-American women was associated with increased paternal contact and resource allocation. The possibility that mothers named children after those fathers who were already more likely to have greater contact with and allocate more resources to their children, of course, cannot be ruled out.

In the subtle negotiations of courtship and marital commitments, it is possible that men may tend to perceive a woman who endorses taking his surname as more attractive and/or more desirable as a mate (regarding desirability, see generally Boxer and Gritsenko 2005; Nugent 2010). It is 
plausible that the quality of a daughter-in-law's relationship with her husband, including the amount he found her attractive and desirable, would impact her relationship with her parents-in-law. As such, greater investment in her children by her parents-in-law could follow from a woman's marital surname change.

Perhaps paternal surname-saking influences some, especially those on the child's father's side of the family, to attribute paternity of the surname-sake to his or her putative father, and therefore infer relatedness to themselves (see generally Hartung 1985 for the theorized importance of this to paternal female as well as male relatives), in a greater set of circumstances than would otherwise be the case. The legitimacy of children born within a marriage is a legal presumption under English common law, rebuttable by evidence that the husband could not have been the biological father (The King v. Luffe 1807). English common law formed the basis of much of that of Canada and the U.S.A. Regardless, the vigorous prescription of the legitimacy of children is seen not just in countries the legal history of which is English common law (see, e.g., Davis 1939 regarding lack of inheritance and non-membership in the parental line for illegitimate children cross-culturally; Korbin 1987 regarding relatively worse treatment of illegitimate children including by family members across several cultures). Surnaming only the children of a marriage for the husband was practiced under English common law, as well as in the U.S.A. Illegitimate children traditionally took the surname of (only) their mother (Thornton 1979). As noted, the vast majority of U.S. children carry solely their fathers' surnames, but this is somewhat less often the case if the mother did not take her husband's name at marriage (Johnson and Scheuble 2002). Thus, if women effectively signal their future children will be similarly surnamed via their own marital surname change, they confer on their husbands the ability to communicate this indication of his biological relatedness to the children of his marriage. This may be a motivator for women's marital surname change: increasing their attractiveness to/pleasing of their husbands, by allowing the latter to signal paternity certainty.

\section{Regional and Jurisdictional Variation}

Quebec women lost the right to take their husbands' surnames as their own other than "socially" in 1980. Quebec possesses significant linguistic as well as other (e.g., historical, cultural) distinctiveness, compared with other North American jurisdictions. Be that as it may, as the sole North American jurisdiction in which it has now generally been impossible for women to formally take their husbands' surnames for over a generation, Quebec's rate of transmission of fathers' surnames to children may serve as a useful comparitor with that rate in other North American jurisdictions within the same timeframe, indicating the effect of women not taking husbands' surnames on child surnaming.
In the last year in which almost all Quebec women who gave birth and were married still had the choice of taking their husbands' surnames at marriage (1980), just $2 \%$ of babies born were surnamed for both mother and father. The like figure for each of the following years is: $1986,15 \% ; 1992,22 \%$; 2000 , $15 \%$; and in 2005, $12 \%$ (Duchesne 2006). The increase in using both parents' surnames when surnaming children, once women could not undergo marital surname change is remarkable: from $2 \%$ in the year brides first had to keep their premarital surnames up to $22 \% 20$ years later. This latter figure appears to sharply contrast with the percentage of children surnamed other than solely patrilineally or given their mother's premarital surname as a middle name, in Johnson and Scheuble's (2002) sample of U.S. married women who had retained or hyphenated their surnames at marriage: $7 \%$. This is especially the case, since the women sampled by Johnson and Scheuble were employees, including faculty, within a system of universities: presumably a sample more likely to be socially progressive and politically left than others. These facts perhaps explain this still apparently high $(7 \%)$ rate of children's surnaming for their mothers as well as their fathers, or being given the mother's surname as a middle name.

Be that as it may, solely patrilineal surnaming of infants, like women's taking of their husbands' surnames, may have experienced a resurgence in Quebec following the 1990s. In 2005, $82 \%$ of infants received solely their fathers' surname: Five percent were given solely their mothers', but in most such cases the father was unknown or undeclared. Only $1 \%$ of infants born to married women received just her surname (Duchesne 2006). Thus, even in the one North American jurisdiction where the formal taking of a husband's surname became prohibited, the tradition of solely patrilineal surnaming for children has been largely maintained for decades. Its pre-eminence as "the" choice for infant surnaming, however, appears to have been seriously eroded starting at the time women no longer had the option of taking their husbands' surnames. This evidence is consistent with patrilineal descent reckoning being a reason for women's marital surname change.

Rationales for women's marital surname change have been found in one U.S. survey to closely relate to social norms (Keels and Powers 2013). "(S)ociodemographic cleavages" such as left- or right-leaning politically have also been found to predict marital surname change in a U.S. study (Hamilton et al. 2011, p. 149). Such political leaning as well as, perhaps, social norms, could be related to region. As noted, a U.S. survey reportedly representative of married individuals showed the prevalence of women taking their husbands' surnames varied by region. Women in the South were most likely to retain their surnames, followed by women in the West, then the Northeast, and finally the North Central region (Johnson and Scheuble 1995: note that the primarily Southern tradition of women retaining their birth surnames as middle names counted as birth surname retention). Surname change in U.S. 
brides may vary systematically with the bride's home state's average women's income level, with greater such level correlating positively with surname retention or hyphenation (MacEacheron 2011). The state-to-state variation found in retention/hyphenation rate among U.S. brides did not accord with regional variation found by Johnson and Scheuble (1995), but did accord with a later finding by these authors plus another (Scheuble et al. 2012). The above state-to-state and perhaps region-to-region variation is consistent with brides, to the degree they are less needy of resource support from husbands and in-laws (see also Scheuble and Johnson 2005 for association of full-time employment status with increased situational use of pre-marital surname), and presumably also less often marrying hypergamously, less often choosing marital surname change.

\section{Changes in Rate of Marital Surname Retention/Change from 1975 or 1985 to Present}

In a 1992 telephone survey presented as representative of the U.S. population, just $1.4 \%$ of 929 still-married respondents, who had been between 19 and 55 years of age and married in 1980, reported that they (if female) or their wife used a surname other than the husband's, or hyphenated the two (Johnson and Scheuble 1995). One of each respondents' ever-married offspring 19 or older in 1992, who had dwelled with the respondent in 1980, were similarly surveyed $(n=180)$. There were $4.6 \%$ who reported that they (if women) or their wives (if men) used a surname other than the husband's, or hyphenated. That is, premarital name retention had tripled in a generation, but remained rather rare. Limited evidence suggests that this increase in women's pre-marital surname retention is not continuing. In 1978 about $10 \%$ of brides marrying in Hawai'i, the only American state requiring brides to indicate their intended surnames, stated they would retain their pre-marital surnames, either using it alone or combining it with that of the husband by hyphenation (Cherlin 1978). Thirty years later, this statistic had increased only to $16.7 \%$ (MacEacheron 2011). In 2010, it was $19.2 \%$ (based on data provided by Brian Y. Horiuchi, Hawai'i State Department of Health, personal communication, January 31, 2013).

According to Goldin and Shim (2004), the percentage of college-educated, Massachusetts women electing to keep or hyphenate their surnames upon marriage may actually have been decreasing since the early 1990s (see also Gooding and Kreider 2010). Kopelman, Shea-Van Fossen, Paraskevas, Lawter, and Prottas (2009), in a study of New York Times wedding announcements between the 1970s and early 2000s, found that brides retaining surname at marriage increased from the 1970 s to the 1990 s, with only a non-significant increase in the practice in the early 2000s. Women advertising their engagement in the New York Times would seem on average to be wealthier than other brides. As such, they may also tend to be better educated, as well as less likely to be marrying hypergamously. Various U.S. studies have shown that the wealthier and more educated a woman, the less likely she is to take, or to express approval of taking, husband's surname (Goldin and Shim 2004; Hoffnung 2006; Johnson and Scheuble 1995, 2005). Relatedly, several U.S. studies have shown that women in positions to earn more money are less likely to take or approve of taking husbands' surnames (Goldin and Shim 2004; Johnson and Scheuble 1995; Kline, Stafford, and Miklosovic 1996; Scheuble and Johnson 1993). Thus, even with increasing gender equity over the given time period, and now decades-long absence of legal requirement, the practice of changing one's surname at marriage remains strong, especially among less-educated, less-wealthy women. It may be that where women need less resource support for themselves and their future children from their husbands, future in-laws, or both, they may less often be seeking to please these others via participation in a custom which, as noted, may achieve that goal, but at a cost to these women.

\section{Others' Perceptions of Women Retaining, Hyphenating, or Changing Pre-Marital Surname}

A sex difference in the perception of women who retain their surnames was observed by Murray (1997): U.S. men, but not women, expressed the view that such women are less attractive and make worse mothers. In Ontario, Canada, male participants also rated women who kept their natal surnames as less attractive (Atkinson 1987). Embleton and King (1984) reported data gathered from customers and staff of a Canadian campus pub and nearby exotic dance club. Slightly more than half of the 43 respondents characterized surname keepers as assertive and job-oriented rather than home- or family-oriented. Surveyed female college students in the U.S.A. Midwest have shown static marital surname change intention, but increased negative attitude toward women not taking husband's surname at marriage - saying these were less committed to the marriage - between 1990 and 2006 (Scheuble, Johnson, and Johnson 2012: see also Robnett and Leaper 2013, in which $30.5 \%$ of women indicating desire to undergo marital surname change gave devotion to husband or "family unity" as a reason). As for women who hyphenate their birth surnames with those of their husbands, one study found U.S. undergraduates perceived them as relatively career oriented, with men scoring high on the "Hostile Sexism Scale" (Glick and Fiske 1996) rating them as relatively likely to violate sexual norms, including committing adultery (Stafford and Kline 1996). Some of the men studied, therefore, might think that brides signal their future commitment to the marriage and to sexual fidelity as well as motherhood, via surname change. The above trend of lesser male than female positive trait attribution to women who retain their premarital surnames may help explain an 
apparent disconnect found in one small, Canadian study. The difference was between unmarried females' preference to retain or hyphenate and unmarried males' expectations regarding their future wives' surnaming decisions. In this study of university students, a majority of females stated they would prefer to engage in non-traditional marital surnaming. Most of the male participants, however, expected their future wives to undergo marital surname change (Lockwood et al. 2011).

A U.S. study showed that women rated women who retain their natal surnames less likely to contravene sexual norms than those who simply take their husbands' names (Forbes et al. 2002). Perhaps such women were seen on some level by other young women yet unlikely to be married and also unlikely to yet understand men's impressions of female marital surname retention, as somehow truer to themselves. In this way, it is possible that assessments of these women's sexual mores benefitted from a halo effect. In a study of married, Catholic, U.S. women, however, any non-traditional marital surnaming practice on the part of women was seen by some respondents as indicating intention to leave the marriage at some point or selfcenteredness (Suter 2004). In a U.S., between-subjects design study, Etaugh et al. (1999) found that undergraduates rated the same hypothetical married women as more communal and less agentic, when they had been told she had taken her husband's surname. Thus, both sexes may tend to view women who retain premarital surname after marriage as less likely to focus on motherhood and more likely to be suited to a career, sexually unfaithful, and more likely to divorce. Women's sexual and marital fidelity would be expected to affect men's reproductive success: perhaps men in positions (e.g., of relative wealth) to expect high reproductive success tend to expect greater indications from their wives of such fidelity.

\section{Additional Demographic and Attitudinal Factors Associated with Marital Surname Retention/Change}

Age (Goldin and Shim 2004; Hoffnung 2006; Johnson and Scheuble 1995; MacEacheron 2011; and see Abel and Kruger 2011; Scheuble and Johnson 1993, 2005), the surname choice of the woman's own mother, cohabitation before marriage, and gender role traditionalism (Johnson and Scheuble 1995) have been found to be predictive of U.S. women's surname decision at marriage. Correlates of traditionalism such as religion, religiosity and cultural background have also been identified as decision predictors, while cohabitation before marriage has been found to predict surname retention or positive attitude thereto (Blakemore et al. 2005; Boxer and Gritsenko 2005; Intons-Peterson and Crawford 1985; Kline et al. 1996; Scheuble and Johnson 1993; Twenge 1997). A discussion of the effects of ultimate cultural background for those living in North America, on women's marital surname change, is beyond the scope of this paper. Feminist self-identification has been correlated with positive attitude to women's surname retention at marriage (Hamilton et al. 2011, and see generally Kerns 2011). It is unclear why the marital surname change/retention choice of one's mother may predict one's own such choice as a daughter. This predictor may be unrelated to recruitment of resources from husband or in-laws.

Women marrying at older ages have been found to be more likely to retain their premarital surnames. MacEacheron (2011), for example, using archival data on all marriages in Hawai'i in 2006, found support for older brides being more likely to retain their premarital surname $\left(\chi_{(1)}^{2}\right.$ for linear trend $=399.60, N=28$, $679, d f=1, p<0.0001)$. There may be several reasons for this. Women who marry at later ages are more likely to be welleducated professionals, for whom name change would have greater financial and professional costs (see generally Goldin and Shim 2004). An older bride is also more likely to have been married previously (see Johnson and Scheuble 1995 for an association between prior marriage and surname retention) and to have children from a former relationship. She may also be less likely to be marrying hypergamously, due to wealthier men tending to marry more attractive women (see Udry and Eckland 1984), and attractiveness tending to decrease with age. From an evolutionary perspective, assuming women's marital surname change is designed, in part, to recruit support for children of the marriage (e.g., by asserting their greater belonging to their husband's rather than their own line), age is especially relevant. That is so, since the closer a woman is to menopause, the fewer future children she can generally expect to have. Such women can, on average, anticipate not needing a spouse's support with young children to the same degree as a woman marrying at a younger age. Given this fact, it is hypothesized that older brides may not seek as much as younger ones to please their husbands in ways that are costly to these women, including via marital surname change.

Women who cohabit before marriage may be lower in religiosity, and, for that reason, less likely to endorse taking husbands' surnames. Religion or religiosity, as well as gender role traditionalism (including feminism), however, speculatively could reflect adherence to traditional sexual mores such as avoiding adultery, generally predicted to be valued by males (for evidence of such valuing, see, e.g., Buss 1989) and leading to increased paternity certainty. Patrilineal descent reckoning, as discussed, is related to more rigorous sanctioning of adulterers cross-culturally, which is in turn related to increased paternity certainty and greater male than female variance in reproductive success. The fact that women tend to change surname more if higher in religiosity or traditionalism may thus reflect a link between such surname change and patrilineal descent reckoning. For example, marital surname change could be a signal by brides of future sexual fidelity which, to the extent such signal is costly for the woman to make, may be relied upon by her groom. The more he perceives such signal as reliable, in turn, the greater the extent to which he can be sure the children of the marriage are related to 
him biologically, and the greater his incentive to invest in them.

\section{Discussion}

Why would brides change surname to that of their grooms, when doing so is often a fraught decision and potentially expensive in terms of earnings (Goldin and Shim 2004)? Clearly, such change is highly normative. Yet a sizable minority, over decades, have broken with that norm, and the U.S. brides who do so are not randomly distributed - state residency and age, for example, are predictive. Women may very well be aware that using husbands' surnames as their own and children of the marriage sharing such surname is something husbands feel strongly about. To the extent their future in-laws will be pleased if these women's husbands are pleased, these women may choose to please both their husbands and in-laws, by signaling fidelity to their husband's (and therefore in-laws') line and the intention to add their future children to it. Given that the future children of brides who take their grooms' surnames at marriage overwhelmingly bear solely these grooms' surnames, such signaling could be effected by marital surname change.

It is at least unclear based on the history of relevant law and practice, that the former legal requirement of women's marital surname change in North America was due to an English common law doctrine. There is arguably better evidence that the practice started as a signaling device on the part of brides, that children of the marriage would be surnamed for their husbands. Now that across Canada and the U.S. brides have not had to change their surnames to those of their husbands for over a generation, presumably it is well known by brides that retention or change (or hyphenation) is a matter of choice. There is now, further, a decades' deep social scientific literature on the practice. This paper sought to use the findings of such work and related work, to elucidate a logical tie between patrilineal descent reckoning and provisioning of wives and children by husbands and husbands' parents, and the custom of women's marital surname change.

One way such logical tie and other factors relating to women's marital surname choice may be investigated, is by comparing the custom across the jurisdictions in which it has been best-studied: the U.S.A. and Canada. Unfortunately, data on the practice is only collected in Hawai' 1 . To the extent there exist important and studyable differences between these jurisdictions, which otherwise share much in common, these differences could be related to rate of women's marital name change and attitudes toward this custom. Thus, I encourage researchers to collect data at the local or jurisdictional level, to allow for such research. Factors associated with women's children bearing their surnames, depending on these women's marital surname change or retention, across jurisdictions, could additionally be compared. As discussed, notwithstanding the prevalence of patrilineal naming practices and descent reckoning, there exists solid empirical evidence that actual interaction and nurturance exhibit a matrilateral bias when both paternal and maternal relatives are accessible. Evolutionists have interpreted these phenomena as a reflection of adaptive variation in grandparental solicitude, based on paternity uncertainty. The phenomenon of matrilateral bias in contact, investment and affection is robust throughout the modern West. Yet the women's marital surname change literature reviewed above shows that this ostensible means of ensuring patrilinealdescent reckoning is also clearly robust in the U.S.A. and Canada.

To the extent marital surname change is difficult or disadvantageous to the woman, it may serve as a reliable marker of fidelity to her husband, to her marriage, or to both. Children bearing the surname of their (married) father is a traditional legal marker of their biological relatedness to him. To the extent legitimacy is (cross-)culturally prescribed, it would be expected to be preferred by grandparents and fathers in offspring. Thus, brides may change surname at marriage in part to signal (1) fidelity to the man they are marrying/marriage, and (2) that their children with the man will be demonstrably legitimate. This may serve to add esteem to the patriline and, speculatively, perhaps even publicly assert the paternity certainty of its males.

This paper has shown limited evidence that men whose children are named after them invest more in them, and that women who undergo marital surname change are perceived as more committed to their husbands, including more sexually faithful. This begs the question whether women's marital surname change might constitute a device to elicit investment in children from husbands and from the category of grandparent least likely to bestow it: the paternal grandfather. Maternal grandparents are more likely to invest in grandchildren, as discussed, and even to do so where paternal grandparents are equally close-by and after divorce. Thus, maternal grandparents may be seen as more certain investors, who need not have their grandchildren surnamed for them in order to ensure their investment.

As noted, the quality of the relationship between daughter(in-law) and parent(-in-law) has been shown to be positively related to the amount and frequency of grandparental involvement with grandchildren. It is plausible that investment by paternal grandparents could increase when grandchildren carry their surname. This could explain why the parents of brides are likely to not object or even desire that their daughters change their surnames at marriage, which desire might otherwise be puzzling. If it is indeed the case that women's marital surname change (and other forms of patrilineal descent reckoning) leads to greater investment by the father and his parents in a woman's children, such advantage attendant on the practice may constitute the most ultimate explanation for it.

Women's choice to not undergo marital surname change will have been acknowledged as legal for all purposes across 
the U.S.A. for between 30 and 40 years at time of writing. Additionally, given the U.S.A.'s cultural influence on Canada, the options of surname retention and hyphenation should have been salient in that country too, for this same amount of time. Even women in states in which it most recently became legal for all purposes to retain pre-marital surname at marriage, who married at that point in time, are now old enough to be grandmothers. Many of their children are of an age to have children themselves, and to face surnaming decisions for these. Thus, it is possible that North American patrilineal descent reckoning, which may be an ultimate reason for marital surname change, will now have been either reclaimed or subverted in some families. Such reclamation could occur as a counter-reaction to the bilateral descent reckoning that implicitly occurs via giving children a dual (both mother's and father's) surname. For example, it might be expressed via increased solely patrilineal surnaming of children, increased change of surname by brides to that of their grooms, or both. In other cases, however, married women who retained their natal surnames and gave their children a dual surname could now have given rise to two generations of less-patrilineal and more fully bilateral descent reckoners.

If patrilineal descent reckoning were an ultimate reason for women's marital surname change, then a negative reaction by husbands and their families to children and grandchildren of women who do not take their husbands' surname being surnamed after their mothers or bilaterally (i.e., both after their mothers and after their fathers) might be expected. This might be especially the case from some quarters. Such particularly negative reaction, for example, could occur in areas of North America, or in particular families, in which reproductive success variance is relatively greater in males. Greater negative reaction to deviations from patrilineality, such as children not receiving solely their fathers' surnames, could occur from inlaws and husbands interested in the concentration of family resources in sons in their patriline. This interest, in turn, is predicted to be due to such concentration most greatly increasing their number of descendants, given that sons in whom resources are concentrated, in a group with relatively higher male compared with female reproductive success, could achieve some form of polygyny (e.g., serial marriages to young women). This would most often be expected to be the case where the family is relatively wealthy. Even in such quarters, however, and more so outside of them, wives' preference if any to not take their husbands' surnames as their own or to not pass (solely) these to their children, may become more and more disadvantageous for husbands and in-laws to attempt to override. The reason for this, is fewer marriages and a declining birth-rate making daughters-in-law (and grandchildren) rarer and more precious, thus increasing their bargaining power within families. A married woman's bargaining power with respect to her in-laws would also tend to be greater, and her need for resources from then less, all else being equal, where she was not engaging in hypergamy. To the extent hypergamy is becoming less frequent, the frequency at which women take their husbands' surnames is predicted to decrease.

Generally, the reaction to children and grandchildren of women who do not take their husbands' surnames being surnamed for their mothers or bilaterally would be expected to be more negative than that to women who retain surname or hyphenate at marriage, but who give the children of the marriage only their husbands' surname. One form of reaction to the loss of patrilineal in favor of bilateral descent reckoning could occur via the surnaming of grandchildren of women who gave their surnames, along with those of their husbands, to their children. For example, such grandchildren could less often than would be predicted under equal passing of all surnames of both parents, bear maternally derived surnames (as occurs in Spanish-speaking countries, in which each individual traditionally bears each of his or her grandfathers' patrilineally derived surnames: e.g., Fuster 1986). Other examples of testable hypotheses as to patrilineal bias in surnaming of infants of couples in which at least one parent has a bilateral surname, are possible. Perhaps in families in which there are both grandchildren (a) bearing only the patrilineal surname and (b) bearing it as well as another, inheritance and other investment on the part of the paternal relatives in the grandchildren could be contrasted for evidence of favoritism toward the former set of grandchildren. If it is found, it would constitute indirect evidence for the utility of patrilineal surnaming in eliciting investment in children from the paternal grandparents.

At this point in history, those opposed to bilaterally surnaming children no longer need to warn that the children of these, in turn, may each end up having four surnames. Researchers should now be able to ask what actually happens in such cases. That is, it should now be possible to ask what tends to be the result when Mr. Smith-Jones and Miss BrownPotter wish to marry - whose surname(s), if any, tend to be sacrificed at the marriage alter, and whose surname(s) will not make it onto their children's birth certificates. Perhaps a patrilineal bias will be apparent in the answers to these questions, and more so to the latter such question, if an ultimate purpose of women's marital surname change is ensuring patrilineal descent reckoning.

Alternately, patrilineal descent reckoning may be changing to become bilateral, at least for children with dual surnames. If patrilineal descent reckoning is cherished or advantageous enough (e.g., to married women and their children) and its loss felt to be imminent given two generation's non-patrilineal surnaming, however, perhaps a shift away from women's marital surname retention will occur. For example, there could be counterreaction to non-patrilineal surnaming, on the basis of desire to not lose patrilineal descent reckoning. This is speculatively proposed as a reason for the desurgence in the 
1990s of women's marital surname retention (e.g., see Goldin and Shim 2004; Duchesne 2006; Kopelman et al. 2009).

\section{Conclusion}

The ultimate purpose of women's marital surname change was posited to be ensuring patrilineal descent reckoning, and enhancement of resource recruitment for children of the marriage by wives, from husbands and in-laws attendant on such reckoning. One replicated finding from the reviewed research, is that where mothers did not take the surname of their husbands their children are more likely to bear their mother's surnames, usually in addition to those of their fathers. Now that the choice for women to not engage in marital surname change has existed for more than one generation, its effects on such reckoning, and enhancement of such resource recruitment, should be assessable. Inter-jurisdictional differences could additionally be used to elucidate factors associated with the practice of women's marital surname change and provide clues as to it cause(s).

Acknowledgments Martin Daly and Margo Wilson helpfully edited an early draft.

\section{References}

Abel, E. L., \& Kruger, M. L. (2011). Taking thy husband's name: the role of religious affiliation. Names: A Journal of Onomastics, 59, 12-24.

Atkinson, D. L. (1987). Names and titles: maiden name retention and the use of MS. Journal of the Atlantic Provinces Linguistic Association, 9, 56-83.

Blakemore, J. E., Lawton, C. A., \& Vartanian, L. R. (2005). I can't wait to get married: gender differences in drive to marry. Sex Roles, 53, 327-335.

Boxer, D., \& Gritsenko, E. (2005). Women and surnames across cultures: reconstituting identity in marriage. Women and Language, 28(2), 111.

Brown, G. R., Laland, K. N., \& Borgerhoff Mulder, M. (2009). Bateman's principles and human sex roles. Trends in Ecology \& Evolution, 24, 297-304.

Buckle, L., Gallup, G. G., Jr., \& Rodd, Z. A. (1966). Marriage as a reproductive contract: patterns of marriage, divorce, and remarriage. Ethology and Sociobiology, 17, 363-377.

Buss, D. M. (1989). Sex differences in human mate preferences: evolutionary hypotheses tested in 37 cultures. Behavioral and Brain Sciences, 12, 1-49.

Camden, W., \& Philipot, J. (1637). Remaines concerning Britaine: their languages, names, surnames, allusions, anagrammes, armories, monies, empreses, apparell, artillarie, wise speeches, proverbs, poesies, epitaphes. Thomas Harper: London.

Chagnon, N. A. (1979). Is reproductive success equal in egalitarian societies? In N. A. Chagnon \& W. G. Irons (Eds.), Evolutionary Biology and Human Social Behavior: An Anthropological Perspective (pp. 374-401). North Scituate, MA: Duxbury Press.

Cherlin, A. (1978). Hereditary hyphens? Psychology Today, December, 150 .
Cherlin, A. J., \& Furstenberg, F. F. (1986). The new American grandparent: a place in the family, a life apart. New York: Basic.

Civil Code of Québec, C.c.Q., 1991, c. 64, a. 58

Daly, M., \& Wilson, M. (1988). Homicide. New Brunswick, NJ: Transaction.

Davenport, W. (1959). Nonunilinear descent and descent groups. American Anthropologist, 61, 557-572.

Davis, K. (1939). Illegitimacy and the social structure. American Journal of Sociology, 45, 215-233.

DeKay, W. T. (1995). Grandparental investment and the uncertainty of kinship. Santa Barbara: Paper presented at the meeting of the Human Behavior and Evolution Society.

Dickemann, M. (1979). Female infanticide, reproductive strategies, and social stratification: A preliminary model. In N. A. Chagnon \& W. G. Irons (Eds.), Evolutionary Biology and Human Social Behavior: An Anthropological Perspective (pp. 321-367). North Scituate, MA: Duxbury Press.

Duchesne, L. (2006). La situation démographique au Québec: Bilan 2006. Government of Quebec. Accessed 10 March 2016, www. stat.gouv.qc.ca/statistiques/population-demographie/bilan2006.pdf

Ellison, P. T. (1994). Extinction and descent. Human Nature, 5, 155-165.

Embleton, S. M., \& King, R. (1984). Attitudes towards maiden name retention. Onomastica Canadiana, 66, 11-22.

Emens, E. F. (2007). Changing name changing: framing rules and the future of marital names. The University of Chicago Law Review, 74(3), 761-863.

Etaugh, C. E., Bridges, J. S., Cummings-Hill, M., \& Cohen, J. (1999). "Names can never hurt me?" The effects of surname use on perceptions of married women. Psychology of Women Quarterly, 23, 819823.

Euler, H., \& Weitzel, B. (1996). Discriminative grandparental solicitude as reproductive strategy. Human Nature, 7(1), 39-59.

Forbes, G. B., Adams-Curtis, L. E., White, K. B., \& Hamm, N. R. (2002). Perceptions of married women and married men with hyphenated surnames. Sex Roles, 46, 167-175.

Furstenberg, F. F., \& Talvitie, K. G. (1980). Children's names and paternal claims. Journal of Family Issues, 1(1), 31-57.

Fuster, V. (1986). Relationship by isonymy and migration pattern in northwest Spain. Human Biology, 58, 391-406.

Glick, P., \& Fiske, S. T. (1996). The ambivalent sexism inventory: differentiating hostile and benevolent sexism. Journal of Personality and Social Psychology, 70, 491-512.

Goldin, C., \& Shim, M. (2004). Making a name: women's surnames at marriage and beyond. Journal of Economic Perspectives, 18, 143160.

Gooding, G. E., \& Kreider, R. M. (2010). Women's marital naming choices in a nationally representative sample. Journal of Family Issues, 31, 681-701.

Goody, J. (1961). The classification of double descent systems. Current Anthropology, 2, 3-25.

Government of Alberta. (n.d.). Legal Change of Name. Accessed 09 Jan 2007, www.servicealberta.gov.ab.ca/vs/name_change.cfm

Government of British Columbia. (n.d.). Frequently Asked Questions Marriage. Accessed 08 Aug 2014, http://www.vs.gov.bc.ca/ questions-marriage.html

Government of Manitoba. (n.d.). Family law in Manitoba -2005 edition, chapter 14-change of name. Accessed 05 June 2008, www.gov. $\mathrm{mb} . c \mathrm{j} /$ justice/family/englishbooklet/chapter14.html

Government of Ontario. (n.d.a.). Changing Information on a Driver's Licence. Accessed 08 Aug 2014, http://www.mto.gov.on.ca/ english/dandv/driver/change.htm

Government of Ontario. (n.d.b.). Changing Your name due to a relationship \& changing it back. Accessed 05 June 2008, http://www.gov. on.ca/ont/portal/!ut/p/.cmd/cs/.ce/7_0_A/.s/7_0_252/_s.7_0_A/7 0_252/_/en?docid=119599 
Hamilton, L., Geist, C., \& Powell, B. (2011). Marital name change as a window into gender attitudes. Gender and Society, 25, 145-175.

Hartung, J. (1976). On natural selection and the inheritance of wealth. Current Anthropology, 17, 607-622.

Hartung, J. (1985). Matrilineal inheritance: new theory and analysis. The Behavioral and Brain Sciences, 8(04), 661-670.

Hawkes, K., O’Connell, J. F., \& Blurton Jones, N. G. (1997). Hadza women's time allocation, offspring provisioning, and the evolution of long postmenopausal life spans. Current Anthropology, 38(4), $551-577$.

Hill, K., \& Hurtado, A. M. (1996). Ache life history. New York: Aldine De Gruyter.

Hoffnung, M. (2006). What's in a name? Marital name choice revisited. Sex Roles, 55, 817-825.

Hrdy, S. B., \& Judge, D. S. (1993). Darwin and the puzzle of primogeniture. Human Nature, 4, 1-45.

Intons-Peterson, M. J., \& Crawford, J. (1985). The meanings of marital surnames. Sex Roles, 12, 1163-1171.

Jackson, J. J. (1971). Aged blacks: a potpourri in the direction of the reduction of inequities. Phylon, 32(3), 260-280.

Jackson, C. (2014). Modernity and matrifocality: the feminization of kinship? Development and Change, 46, 1-24.

Johnson, D. R., \& Scheuble, L. K. (1995). Women's marital naming in two generations: a national study. Journal of Marriage and the Family, 57, 724-732.

Johnson, D. R., \& Scheuble, L. K. (2002). What should we call our kids? Choosing children's surnames when parents' last names differ. The Social Science Journal, 39(3), 419-429.

Kahana, B., \& Kahana, E. (1970). Grandparenthood from the perspective of the developing grandchild. Developmental Psychology, 3(1), 98 105

Keels, M. M., \& Powers, R. S. (2013). Marital name changing: delving deeper into women's reasons. Advances in Applied Sociology, 3(07), 301

Kerns, M. (2011). North American women's surname choice based on ethnicity and self-identification as feminists. Names: A Journal of Onomastics, 59, 104-117.

Kline, S. L., Stafford, L., \& Miklosovic, J. C. (1996). Women's surnames: decisions, interpretations and associations with relational qualities. Journal of Social and Personal Relationships, 13(4), 593-617.

Kopelman, R. E., Shea-Van Fossen, R. J., Paraskevas, E., Lawter, L., \& Prottas, D. J. (2009). The bride is keeping her name: a 35-year retrospective analysis of trends and correlates. Social Behavior and Personality: An International Journal, 37, 687-700.

Korbin, J. E. (1987). Child maltreatment in cross-cultural perspective: vulnerable children and circumstances. In R. J. Gelles \& J. B. Lancaster (Eds.), Child abuse and neglect: biosocial dimension (pp. 31-55). New Jersey: Aldine Transactions.

Liss, M., \& Erchull, M. J. (2012). Differences in beliefs and behaviors between feminist actual and anticipated mothers. Psychology of Women Quarterly, 37, 381-391.

Lockwood, P., Burton, C., \& Boersma, K. (2011). Tampering with tradition: rationales concerning women's married names and children's surnames. Sex Roles, 65, 827-839.

MacClintock, H. (2010). Sexism, surnames, and social progress: the conflict of individual autonomy and government preferences in laws regarding name changes at marriage. Temple International and Comparative Law Journal Ab, 24, 277-312.

Marlowe, F. W. (2004). Marital residence among foragers. Current Anthropology, 45, 277-284.

MacEacheron, M. D. (2011). Hawaii Data: Women's Marital Surname Change by Bride's Age and Jurisdiction of Residence. Names. $A$ Journal of Onomastics, 59, 4-11.

Murdock, G. P. (1949). Social structure. New York: Macmillan.
Murray, T. E. (1997). Attitudes toward married women's surnames: evidence from the American Midwest. Names: A Journal of Onomastics, 45, 163-183.

Nugent, C. (2010). Children's surnames, moral dilemmas: accounting for the predominance of fathers' surnames for children. Gender and Society, 24, 499-525.

Roberto, K. A., \& Stroes, J. (1992). Grandchildren and grandparents: roles, influences, and relationships. International Journal of Aging Human Development, 34(3), 227-239.

Robins, L. N., \& Tomanec, M. (1962). Closeness to blood relatives outside the immediate family. Marriage and Family Living, 24, 340 346.

Robnett, R. D., \& Leaper, C. (2013). "Girls Don't Propose! Ew.”: a mixed-methods examination of marriage tradition preferences and benevolent sexism in emerging adults. Journal of Adolescent Research, 28, 96-121.

Scheuble, L., \& Johnson, D. R. (1993). Marital name change: plans and attitudes of college students. Journal of Marriage and the Family, $55,747-754$.

Scheuble, L., \& Johnson, D. R. (2005). Married women's situational use of last names: an empirical study. Sex Roles, 53, 143-151.

Scheuble, L., Johnson, D. R., \& Johnson, K. M. (2012). Marital name changing attitudes and plans of college students: comparing change over time and across regions. Sex Roles, 66, 282-292.

Schneider, D. M., \& Cottrell, C. B. (1975). The American Kin Universe: a genealogical study. The University of Chicago studies in anthropology series in social, cultural, and linguistic anthropology, No. 3. Chicago: University of Chicago.

Sear, R., Mace, R., \& McGregor, I. A. (2000). Maternal grandmothers improve nutritional status and survival of children in rural Gambia. Proceedings of the Biological Sciences, 267(1453), 1641-1647.

Sear, R., Steele, F., McGregor, I. A., \& Mace, R. (2002). The effects of kin on child mortality in rural gambia. Demography, 39(1), 43-63.

Shackelford, T. K., Michalski, R. L., \& Schmitt, D. P. (2004). Upset in response to a child's partner's infidelities. European Journal of Social Psychology, 34(4), 489-497.

Smith, M. S. (1988a). Research in developmental sociobiology: parenting and family behavior. In K. MacDonald (Ed.), Sociobiological perspectives on human development (pp. 271-292). New York: Springer-Verlag.

Smith, M. S. (1988b). An Evolutionary Perspective on grandparentgrandchild relationships. Papers presented to Third European Conference on Developmental Psychology, Budapest, Hungary, June 1988, Tenth Meeting of the International Society for the Study of Behavioural Development, Jyvaskyla, Finland, July 1989, and the Developmental Section Meeting of the British Psychological Society, Harlech, U.K., September 1988. In P. K. Smith (Ed.), (1991). The Psychology of Grandparenthood: An International Perspective pp (155-175). New York: Routledge

Smith, M. S., Kish, B. J., \& Crawford, C. B. (1987). Inheritance of wealth as human kin investment. Ethology and Sociobiology, 8, 171-182.

Snyder, K. (2009). All names are not equal: choice of marital surname and equal protection. Washington University Journal of Law \& Policy, 30, 561-587.

Stafford, L., \& Kline, S. L. (1996). Women's surnames and titles: men's and women's views. Communication Research Reports, 13, 214 224.

Stanton, M. E. (2006). Patterns of kinship and residence. In B. B. Ingoldsby \& S. D. Smith (Eds.), Families in global and multicultural perspective (2nd ed., pp. 79-98). California: Sage.

Suter, E. A. (2004). Tradition never goes out of style: the role of tradition in women's naming practices. The Communication Review, 7, 5787.

Sylvester, K. M. (1998). "En part égale": family, inheritance, and market change in a Francophone community on the Prairies, 1880-1940. 
Journal of the Canadian Historical Association/Revue de la Société historique du Canada, 9(1), 39-62.

The King v. Luffe, 103 Eng. Rep. 316 (K.B. 1807).

Thornton, R. H. (1979). Controversy over children's surnames: familial autonomy, equal protection and the child's best interests. Utah Law Review, 2, 303-345.

Twenge, J. M. (1997). "Mrs. His Name": women's preferences for married names. Psychology of Women Quarterly, 21, 417-429.
Udry, J. R., \& Eckland, B. K. (1984). Benefits of being attractive: differential payoffs for men and women. Psychological Reports, 54(1), $47-56$.

van Caenegem, R. C. (1988). The birth of the English common law (2nd ed.). Cambridge: Cambridge University Press.

Young, M., \& Willmott, P. (1957). Family and kinship in East London. London: Routledge \& Kegan Paul.

Zaher, C. (2002). When a woman's marital status determined her legal status: a research guide on the common law doctrine of coverture. Law Library Journal, 94, 459-485. 